\title{
Globalization and Language Use on Social Media in Pakistan
}

\author{
Shanzay Kamran \\ Sabiha Mansoor \\ Research Associate, Professor of English
}

\begin{abstract}
This article examines the written comments of Pakistani students on the official Facebook sites of the public and private sector universities in order to study their English language skills and social networking systems of students and its implications for language policy in education. The study focused on the quantitative and statistical analysis and investigated the differences of Facebook users from the public and private sector in the light of educational background, regional variation, and gender. Results of the study displayed the dominant use of English and a significant difference between public and private sector students in their preference to use English. Results also showed that there is considerable differences in men and women representation on Social Networking Sites (Facebook) in some provinces of Pakistan. Findings of the study raise the issue of language discrimination between students of public and private sector universities, in terms of access and equity of the current language policy in Pakistan to meet language demands of globalization.
\end{abstract}

Keywords: Globalization and Language Use on Social Media in Pakistan

\section{Introduction}

This article presents a critical analysis of a corpus of Facebook comments by university students in context on official Facebook sites of both public and private universities in Pakistan. The aim of the study was to understand how this popular social networking site reflects the Pakistani graduate competency in English required for internet technology for local and global communication. The critical quantitative analysis of Facebook comments was used to investigate linguistic discrimination, if any, between students from public and private sector universities, various regions of Pakistan, and gender in terms of access and equity. The aim was to assess if the languages used by subjects reflected their ease in using the language and an assertion of their identity and culture; or conversely due to inadequacy to express themselves in written English.

This paper presents a pioneering study of computer-mediated communication (CMC) through comments of students posted on the fairly recent official social networking sites (Facebook) of a number of public and private HEC approved universities of Pakistan. The major aim of the study was to examine if the current language policy in education was preparing students to have adequate English language skills to meet the current and future demands of globalization for individual and national socio economic advancement.

\section{Background: Language and Education in Pakistan}

Pakistan is a multilingual and multicultural state with a population of around 182.1 million (World Bank, US Census Bureau 2013). The national official language Urdu though mother tongue of only $7.5 \%$ of the population enjoys a high status as a symbol of national identity and integration. English as an international lingua franca, enjoys a high status The 1973 Constitution of Pakistan (article 251) projected that Urdu would replace English as the official language within 15 years. However, due to a number of factors including lack of Urdu materials, English remains the 'defacto' official language and medium of higher education. Despite being the mother tongue of a small population; Urdu and English are regarded as 'majority' languages as they enjoy a high status and are used by the powerful institutions in Pakistan for official purposes and for education. The language policy has always encouraged these two languages at the cost of regional languages that are the mother tongue of the large majority of population in Pakistan. 


\section{Theoretical Framework}

Facebook and Language Change: Internet, as the major influential means of communication in this globalized world, is constantly changing the way people communicate with each other. Social media has resulted in the increased usage of acronyms which are substituting long phrases on the internet. BRB (be right back), LOL (laugh out loud), ttyl (talk to you later) are few examples of how internet users tend to use acronyms instead of full sentences over the social media in order to save time. Mehmood.S \& Taswir. T, (2013) explored the effects of social networking sites on undergraduate students at College of Applied Sciences in Oman and found out that around $58 \%$ of the student acknowledged the change in their language or style of discourse through social media. Media acts as a powerful driver that represents the bias in communication in such subtle ways that the reader and viewer imbibe the messages without even knowing it (Siddiqui.S 2014).

Language and Culture: Anthropologists around the world define culture in terms of day to day practices arising from normative attitudes of a group of people whose interactions are shaped by specific forms of social organizations. Social media has provided a platform where people from different cultures come together and interact with each other. Intercultural dialogue, and thus language especially English; is of great importance in our globalized world where different cultural backgrounds interact daily with each other through influential social media like Facebook, Instagram, Twitter, and Viber. Saleem. N (2015) explored the effects of Social Networking Sites on family interactions and their roles in undermining family bonds along with face to face conversations. This study found out that there is a strong correlation between isolation and the time spent on a social networking site. Sawyer. R (2011) found out that social media is primarily used as a tool to integrate people into their cultures while adapting the new cultures. Her paper examined the effect of social media on the intercultural adaptation process. According to her, interaction and communication are the main tools that affect intercultural adaptation through social media.

Language and Gender: Studies that have discourse as their primary concept are becoming immensely popular in the field of gender and language over the past two decades. Gendered discourse is the term linked to Jane Sunderland's (2004) approach that focuses on the identification of gendered discourses through traces in language use. This approach of Sunderland is related to the analysis called Feminist Critical Discourse Analysis (FCDA), which essentially links CDA and female linguistics. FCDA is primarily used where the critique is needed on the discourses containing patriarchal social order in them. This analysis looks into the unequal gender relations that are obvious in the language use, so as to emancipate and transform.

Keeping in view the scarce literature and paucity of research publications on the impact of globalization and social media from a linguistic point of view in Pakistan, thisresearch study was designed to look into various features of the written discourse of university students through their comments on Facebook of their university website.

\begin{tabular}{|l|l|}
\hline Public Universities & Private Universities \\
\hline Punjab - 45 students' fb comments & Punjab - 30 students' fb comments \\
Sindh - 45 students' fb comments & Sindh -30 students' fb comments \\
Balochistan -5 students' fb comments & Balochistan -5 students' fb comments \\
Khyber Pakhtunkhawa - 20 students' fb comments & Khyber Pakhtunkhawa - 10 students' fb comments \\
Islamabad - 20 students' fb comments & Islamabad - 10 students' fb comments \\
\hline
\end{tabular}

\section{Method}

The present study adopted a combined quantitative and qualitative approach. Both descriptive and statistical analysis were used to find out if the differences were significant or not between students comments in terms of public and private sector universities, regional variation, and gender. One way Analysis of Variance (ANOVA) and Chi Square tests were used to examine the statistical associations between these above mentioned factors.

The qualitative approach was adopted to understand the differences in students' comments on Facebook keeping in view the context in which they were made.

\section{Sample}

In Pakistan, there are currently 129 universities in both public and private sector recognized by Higher Education Commission. To find an appropriate and reliable sample of subjects, a two-stage cluster sampling was used for this study. 
In the first stage, 18 Higher Education Commission (HEC) recognized universities as listed in HEC 2015 ranking list of a total of 129 universities, were selected through purposive sampling on the basis of ratio in number, of public (11) and private universities (7) in Pakistan along with regional variation. Another consideration was size of population of universities and HEC ranking. (See Table 1 below).

\begin{tabular}{|l|l|}
\hline Public Universities & Private Universities \\
\hline Punjab -3 universities & Punjab -2 universitivies \\
Sindh -3 universities & Sindh -2 universities \\
Balochistan -1 university & Balochistan -1 university \\
Kyhber Pakhtunkhawa -2 universities & Kyhber Pakhtunkhawa -1 university \\
Islambad -2 universities & Islamabad -1 university \\
\hline
\end{tabular}

Table 1: Sample of public and private universities

In the second stage, the students' comments were selected randomly. As seen in Table 2, the study comprises around 220 students who posted on official Facebook university sites by the students in the provinces of Pakistan. Table 2: Sample of students FB comments.

The data was collected on an excel sheet developed by the researchers in collaboration with the statistical advisor. The data collectors were university students who volunteered to be involved with the study; were trained on how to fill in the excel sheet; and data was collected in the university computer center under the direct supervision of the researchers.

Quantitative analysis was used to determine the: (1) language(s) used in public \& private university Facebook sites; (2) level of formality in language use in Public \& Private universities; (3) area and topic of discussion; (4) percentage of FB comments by gender in public and private universities; (5)men \& women as active Facebook users by region. The criteria for assessing the level of formality was taken from Pearce (2005) and a study by Perez Sabater et al. (2008). The corpus was analyzed using a 5 point scale, starting from 'very formal' to 'very informal as seen below. An excel sheet was developed and used by data collectors through computers to analyze the data.

\section{Results}

Table 3: Language use in public \& private university Facebook sites

\begin{tabular}{|l|l|l|}
\hline $\begin{array}{l}\text { Languages used on } \\
\text { Facebook comments }\end{array}$ & Percentages of Languages users \\
\hline & Public & Private \\
\hline English & $44 \%$ & $66 \%$ \\
\hline Urdu & $25 \%$ & $13 \%$ \\
\hline Regional & $1.5 \%$ & $2.4 \%$ \\
\hline Mixed (Code switching) & $28 \%$ & $18 \%$ \\
\hline
\end{tabular}

Table 4: Level of formality in language use in public \& Private universities \%

\begin{tabular}{|l|l|l|l|}
\hline & Formal \% & Informal \% & Neither formal nor informal \% \\
\hline Public & 36 & 59 & 5 \\
\hline Private & 47 & 33 & 20 \\
\hline
\end{tabular}

Dominant Language Used: The findings of the present study displayed English to be the most dominant and frequently used language by the Facebook users in public and private universities, with private university students showing a significantly higher preference for use of English (see Table 3).

The languages used in Facebook comments by students from public and private universities, around $44 \%$ of the comments on public university Facebook sites and $66 \%$ on private university Facebook sites were in English. Though Urdu comments were used by $25 \%$ of public sector students and $13 \%$ private sector students, they were written in English Roman transliteration. The regional languages of the provinces of Pakistan were seldom used in any of the Facebook comments 
by both public $1.5 \%$ and private sector $2.4 \%$ students. The comments in the regional language on Facebook were used by the students in KPK and Baluchistan, who used Pashto; and the use of Sindhi by a few students from Sindh. There were no comments in Punjabi by university students of Punjab. While posting comments on the university Facebook site, code mixing and language crossing was used by almost a quarter of all students. The students from public university (28\%) and $18 \%$ of students from private university used code mixing in their comments of English and Urdu, or English and regional language, or all three languages.

Preference for English: As seen in Table 5, a significant difference between the public and private sector university students in terms of preference for English.

Level of Formality and Context: Another important finding of this study was the difference in level of formality shown in the comments in public and university Facebook sites. Table 4 exhibits the percentage of level of formality in public and private Facebook university sites. The students from public universities (59\%) were more informal in the written discourse while posting comments than private university students $(33 \%)$. Private sector students also made use of semi-formal comments $(20 \%)$ on Facebook, as compared to very few students (5\%) from public sector.

Topic of discussion: Another finding suggested that the social context and topic of Facebook comments in public university sites was largely university related (see Table 6). On the other hand, Facebook users on private university sites posted comments which were both personal and university related, with percentage of personal comments being higher than university related comments.

Table 6: Topic of FB comments in public \& private university \%

\begin{tabular}{|l|l|ll|}
\hline & University related & & Personal \\
\hline Public universities & $62 \%$ & $38 \%$ & \\
\hline Private universities & $47 \%$ & $53 \%$ & \\
\hline
\end{tabular}

The language used in terms of formality or informality was also dependent on the topic: Informal language was used for personal context and formal language was used for university related issue.

Topics on complaints and religious matters usually were in informal discourse. The topics observed on both public and private university Facebook sites were mainly related to institutional loyalty, advertisements, alumni discussions, employment opportunities and humor and wit, and concern for admissions. Religious and political connotations were mainly seen on public university Facebook sites; especially from Baluchistan and Khyber Pukhtunkhwah.

Language Change: Students from both public and private sector universities were seen to use acronyms and slangs in their comments.

\begin{tabular}{|c|c|c|}
\hline $\begin{array}{l}\text { Digital Divide in Public/Private Universities in use } \\
\text { of Social Media Networking }\end{array}$ & ANOVA & No significance \\
\hline Gender Norms of Social Media Networking & $\begin{array}{l}\text { Nonparametric } \\
\text { tests }\end{array}$ & Not significant \\
\hline $\begin{array}{l}\text { Types of University (public/private) \& preference } \\
\text { for English }\end{array}$ & ANOVA & $\begin{array}{l}\text { Students/users of FB in private universities have } \\
\text { statistically higher preference for English usage }\end{array}$ \\
\hline $\begin{array}{l}\text { Type of University (Public/Private) \& Preference } \\
\text { for formal/informal language }\end{array}$ & ANOVA & Not significant \\
\hline Gender norms of level of formality & Chi Square & $\begin{array}{l}\text { Level of formality statistically independent with the } \\
\text { gender ratios in different universities }\end{array}$ \\
\hline $\begin{array}{l}\text { Preference for English \& Preference for } \\
\text { formal/informal language }\end{array}$ & Chi square & $\begin{array}{l}\text { Preference of English found independent of the } \\
\text { Preference for formal/informal language }\end{array}$ \\
\hline $\begin{array}{l}\text { Association between preference for } \\
\text { formal/informal language \& the feedback effect }\end{array}$ & Chi square & Statistically insignificant \\
\hline Ratio of Feedback \& preference for English & Chi square & $\begin{array}{l}\text { Weak causality between Ration of Feedback \& } \\
\text { preference for English }\end{array}$ \\
\hline
\end{tabular}

Hopper (1998) views grammar as the product of interactive communication and not the cause. 
Language \& Identity: Comments posted on university Facebook site displayed that in KPK and Baluchistan some of the

\begin{tabular}{|l|l|l|l|l|l|l|l|l|}
\hline Table 7: percentage of FB comments gy gender \\
\hline $\begin{array}{l}\text { Public } \\
\text { universities \% }\end{array}$ & $\begin{array}{l}\text { Private } \\
\text { universities \% }\end{array}$ & $\begin{array}{l}\text { Male } \\
\%\end{array}$ & $\begin{array}{l}\text { Female } \\
\%\end{array}$ & Punjab \% & $\begin{array}{l}\text { Sindh } \\
\%\end{array}$ & $\begin{array}{l}\text { KPK } \\
\%\end{array}$ & Balochistan \% & Islamabad \% \\
\hline 61 & 39 & 62 & 38 & 34 & 34 & 14 & 5 & 14 \\
\hline
\end{tabular}

students used Pashto and only a few students used Sindhi in Sindh. Students from other provinces especially in Punjab preferred to comment in English or / and Urdu in Roman English transliteration. According to Cyber Atlas (2003), the advancements in the internet and technology have resulted in the emergence of English as the Lingua Franca in our globalized world. Thus, with technology and new social media, the impact of English on local languages has increased more than ever.

Language and Gender: Table 7 displays simple percentage of Facebook comments from public or private universities in terms of proportion of males and females posting the comments and regional variation.

Out of the total 220 student comments, $62 \%$ were male comments and $38 \%$ were female'.

Table 8 shows gender norms on university Facebook sites in all provinces in Pakistan.

Table 8: Men \& Women Representation Province wise \%

\begin{tabular}{|l|l|l|l|l|l|l|}
\hline & $\begin{array}{l}\text { Punjab } \\
\%\end{array}$ & $\begin{array}{l}\text { Sindh } \\
\%\end{array}$ & $\begin{array}{l}\text { KPK } \\
\%\end{array}$ & $\begin{array}{l}\text { Islamabad } \\
\%\end{array}$ & $\begin{array}{l}\text { Balochistan } \\
\%\end{array}$ & $\begin{array}{l}\text { Total } \\
\%\end{array}$ \\
\hline Men & 56 & 53 & 63 & 73 & 90 & 62 \\
\hline Women & 44 & 47 & 37 & 27 & 10 & 38 \\
\hline
\end{tabular}

Males are dominating the university Facebook sites with Punjab and Sindh showing relatively less difference in female and male university Facebook usage. On Baluchistan and KPK university Facebook sites, the difference between men and women as active Facebook users as observed in comments posted, is worth noting. In Baluchistan, with almost $90 \%$ of the male's comments compared to $10 \%$ female comments, makes it evident that the females in higher education are invisible and silent. In KPK, the domination of males as active Facebook users is evident by their comments (63\%) as compared to only $37 \%$ female comments. The comments show also how women make more use of emoticons and images to express their emotions as compared to men, who are generally expected to express less in our society.

\section{Results and Discussion}

Linguistic Discrimination: The study findings display that the importance of English has increased for university graduates in the modern world due to globalization and technology including Pakistani university students. It was also seen that the most frequent use of comments in English on the Facebook

on the official website of their universities by both private and public students in universities of Pakistan, is the result of spread of English due to its high status and prestige; as well as being the most widely used lingua franca globally. In addition, fluency to English, is linked with power; and seen as a tool for empowerment. This study shows that the private sector students use English more than public sector universities and display a significantly higher preference for use of English have studied in English medium schools; whereas the public sector students make use of English along with code mixing due to their lack of ease in using English.

Language Change: The use of acronyms in comments by university students on Facebook displayed a language change often referred to as the internet language being different from the language used by students for written language in classrooms. Code mixing was more frequently used by public sector students even in comments for formal use. The everevolving nature of the communication on social media is continuously altered and regenerated.

Language and Gender: The study displayed more male as active FB users in Baluchistan and KPK. It was seen that the comments posted by the females were mostly in emotional vocabulary and their comments were mainly related to nostalgia, fashion, women moving ahead, diet and party arrangements. Gender polarization is the process that makes it easier to restrict opportunities and exclude women and girls from education, military and public platforms (Bing and Bergvall, 1996). Education and language tend to play vital roles in the construction and perpetuation of certain stereotypes against women 
and girls in public platforms Educational system helps in constructing and magnifying differences in class and boundaries in our country mainly through favoring dominant language, dominant culture, and pedagogical practices (Siddiqui.S, 2014).

\section{Recommendations}

Based on the democratic principle, Pakistan must ensure equal opportunities to all its citizens so as to develop themselves personally and professionally. The results of this study display linguistic discrimination between private and public sector students that must be diminished by improving English Language Teaching (ELT) programmes of public sector schools and university, keeping in view the current and future English language skills required by Pakistani graduates for intra and international communication through Social Networking Sites.

The lack of participation of females in Facebook, especially in backward areas like Baluchistan and KPK, is a major concern for women development in Pakistan. It is important for the socio-economic development in Pakistan that the female graduates participate fully as active FB users so that they can be socially integrated in the educational institutions.

In terms of ethno-linguistic vitality of regional languages, state must enhance the status and role of these local languages, especially Punjabi, and strengthen them by integrating them into the educational process of Pakistani students. This would help result in Pakistani graduates emerge as additive bilinguals and not subtractive bilinguals.

Social networking sites have been affecting the social as well as cultural fabric of our societies and have been revolutionizing the pattern of our communication, socialization and interaction. Findings of this study underscore the need to investigate the language needs of university students for English for social media and the learner difficulties.

\section{REFERENCES}

[1] Aitchison, J. (1995). Linguistics: An Introduction. UK: Hodder \& Stoughton.

[2] Atlas, C. (2003). Population explosion Retrieved July 12, 2003 from http://cyberatlas.internet.com/big_picture/geographics/article/0,5911_151151,00.html.

[3] Bing, J.M., \& Bergvall, V.L. (1996). The question of questions: Beyond binary thinking. In V.L.Bergvall, J.M.Bing, \& A.F.Freed, (Eds.), Rethinking language and gender research: Theory and practice (pp. 1-30). New York : Longman

[4] Hopper, J. (1998). Emergent Grammar. In M. Tomasello (Ed.), The New Psychology of Language: Cognitive \& Functional Approaches to Language Structure (pp. 155-175).

[5] Mehmood, S., \& Taswir, T. (2013). The effects of Social Networking Sites on the Academic Performance of students in College of Applied Science, Oman. International Journal of Arts \& Commerce, 2 (1).

[6] Rahman, T. (2009). Language Ideology, Identity \& the Commodification of Language in the Call Centres of Pakistan. Language in Society, (38), 1-26.

[7] Saeed, A. (2013). Women Empowerment in the Light of Female linguistic Trends. Journal of Language, Linguistics \& Literature, (1).

[8] Saleem, N. (2015). Influence of Social Networking Sites on Interaction Patterns of Youth: A Pakistan Case.

[9] Sawyer, R. (2011). The Impact of New Social Media on Intercultural Adaptation. Senior Honors Project. Paper 242.

[10] Siddiqui, S. (2014). Language, Gender and Power. Oxford University Press.

[11] Sunderland, J. (2004). Gendered Discourses. London: Palgrave

[12] Tannen, D. (1992). Rethinking power and solidarity in gender and dominance. In Claire Kramsch \& Sally McConnellGinet (eds.). Text and context: Cross-disciplinary perspectives on language study. Lexington, MA: D.C. Heath. 135147. 